\title{
Optimizing of microfunnel-supported liquid-phase microextraction for the extraction of chlorophenoxyacetic acids in seawater samples
}

\author{
Abolfazl Saleh* ${ }^{1}$, Sara Abedi ${ }^{2}$, Shahab Shariati $^{2}$, Saeideh Molaei ${ }^{3}$ \\ 1- Iranian National Institute for Oceanography and Atmospheric Science, \\ No. 3, Etemadzadeh St., Fatemi Ave., Tehran 1411813389, Iran \\ 2- Department of Chemistry, Rasht Branch, Islamic Azad University, Rasht, Iran \\ 3- Faculty of Chemistry, Kharazmi University, 43 Mofateh Ave., Tehran 1571914911, Iran
}

Received: December 2016

Accepted: March 2017

(C) 2017 Journal of the Persian Gulf. All rights reserved.

\begin{abstract}
In this study, microfunnel-supported liquid-phase microextraction method (MF-LPME) was optimized and applied for the determination of some chlorophenoxyacetic acids (CPAAs) from natural water samples. The extraction was performed with $540 \mu \mathrm{L}$ toluene which was retained at the surface of the sample solution using an upside down microfunnel. After the extraction, toluene was moved into the narrow stem of the microfunnel by pushing the device inside the sample. Then, using a microsyringe, it was transferred into micro vial followed by evaporation using a gentle stream of nitrogen. The residual re-dissolved into $50 \mu \mathrm{L}$ acetonitrile, diluted to $100 \mu \mathrm{L}$ with deionized water and analyzed applying a high performance liquid chromatography equipped with a UV detector (HPLC-UV). Central composite design (CCD) was used for the optimization of factors influencing the extraction. Under the optimized conditions, the limits of detection were 0.42 and $0.43 \mathrm{ng} \mathrm{mL}^{-1}$ for 2,4-dichlorophenoxyacetic acid (2,4-D) and 4-chloro-2-methylphenoxyacetic acid (MCPA), respectively. Preconcentration factors of 66 and 80 were obtained for 2,4-D and MCPA, respectively. The precision of the technique was evaluated in terms of repeatability which was less than $11.1 \%$ $(n=5)$. The applicability of the proposed method was evaluated by the extraction and determination of CPAAs from some natural water samples.
\end{abstract}

Keywords: Microfunnel; Liquid-phase microextraction; Chlorophenoxyacetic acids; 2,4-D; MCPA; Seawatert

\section{Introduction}

Because of widespread usage of pesticides, contamination of the environment especially in the

\footnotetext{
*Email: saleh@inio.ac.ir
}

developing countries is steadily growing. Herbicides seem to be one of the most important categories of the available pesticides (Barcelo and Hennion 1997, Leganes and Fernandez-Valiente 1992, Ogg and Young 1991). Chlorophenoxyacetic acids (CPAAs) are an important group of herbicides widespread in 
agriculture, industries, weed-control and forestry (Alan et al. 1991, Ware 2000, Alexander et al. 1985). The CPAAs used in the present study are 2, 4dichlorophenoxyacetic acid (2,4-D) and 4-chloro-2methylphenoxyacetic acid (MCPA), which are being more frequently used in Iran (Yamini and Saleh 2013). Due to their physical and chemical properties and also their water solubility, monitoring of these contaminants in different environmental matrices especially water samples are highly recommended (Grabińska-Sota et al. 2003). Various analytical techniques have been used for determination of CPAAs by solid-phase extraction (SPE), solid phase microextraction (SPME), dispersive liquid-liquid microextraction (DLLME), automated dynamic liquid-liquid-liquid microextraction (DLLLME), dynamic hollow-fiber liquid phase microextraction (DHF-LPME) and ultrasound assisted emulsification microextraction (Yamini and Saleh 2013, Butz et al. 1994, Majzik et al. 2006, Ebrahimi et al. 2016, Wells and Yu 2000, Ding et al. 2000, Rodríguez et al. 2005, Farhadi et al. 2008, Wu et al. 2005, Esrafili et al. 2011, Hassan et al. 2011).

Recently, bell-shaped extraction device assisted liquid-liquid microextraction (BSED-LLME), based on applying a low-density organic solvent was introduced by Čabala and Bursová (2012). In this approach, the extraction of some organic compounds from mineral and drinking water samples was carried out through specially designed bell-shaped extraction device (BSED). The main advantage of this method is simple and rapid manipulation with the extraction solvent and aqueous sample. With approximately the same principle, Saleh et al. introduced a LPME technique based on the use of modified microfunnel device (MF-LPME) for the extraction and determination of antifouling agents in seawater samples (Saleh et al. 2014). The possibility of utilizing large volume of water sample and small volume of extraction solvent resulted in achieving low limits of detection in this method. In MF-LPME, during the extraction, the wide mouth of the device is tangent to the surface of the sample through edges which leads to a minimum interference in mixing efficiency and maximum possible surface contact between organic solvent droplet and water sample with almost no solvent loss by evaporation. Considering the advantages of this method, in current study, central composite design (CCD) was used to optimize MF-LPME for the preconcentration and determination of MCPA and 2, 4-D in fresh and seawater samples. In this method, the extraction of an aqueous solution with a volume of about $300 \mathrm{~mL}$ was carried out with introduction of a rather small volume of solvent less dense then water to the MF device placed on top of the sample surface through the stopper. After the extraction, the organic solvent containing analytes was withdrawn via a syringe and its solvent evaporated by $\mathrm{N}_{2}$ purging. The residual re-dissolved in acetonitrile, diluted with deionized water and injected into the HPLC for analysis. The influence of different effective variables was investigated and optimized using CCD approach.

\section{Materials and Methods}

\subsection{Reagents and chemicals}

2, 4-dichlorophenoxyacetic acid (2,4-D) and 4chloro-2-methylphenoxyacetic acid (MCPA) were purchased from Accu Standards (New Haven, CT, USA). Stock standard solutions of 2,4-D and MCPA were prepared in HPLC-grade acetonitrile purchased from Samchun (Seoul, South Korea). HPLC grade methanol was purchased from Samchun. All standard solutions were stored at $4{ }^{\circ} \mathrm{C}$ and protected from light. Toluene, $n$-hexane, $n$-heptane and dichloromethane (DCM) were purchased from Merck (Darmstadt, Germany) and used as extraction solvents. Sodium hydroxide and sodium dihydrogen phosphate were purchased from Merck. Water used in the experiment was purified on a Milli-Q ultrapure water purification system purchased from 
Millipore (Bedford, MA, USA). All the other chemicals used were of reagent grade or of the highest purity available. Plastic and glassware used for the experiments were washed with acetone and rinsed carefully with doubly distilled water.

\subsection{MF-LPME procedure}

To extract CPAAs using MF-LPME procedure, a volume of $300 \mathrm{~mL}$ of an aqueous solution containing the analytes was introduced into a $250 \mathrm{~mL}$ Erlenmeyer flask. A small magnetic $\operatorname{rod}(0.5 \mathrm{~cm} \times$ $2.5 \mathrm{~cm}$ ) was inserted and the flask was closed with a rubber septum cap through which an upside-down glass microfunnel (MF) device passed. The wide mouth of the device was immersed about $1 \mathrm{~mm}$ below the surface of aqueous sample and $540 \mu \mathrm{L}$ of toluene was added to the surface of sample through the upper narrow stem of the MF device by using a 1 $\mathrm{mL}$ syringe (Hamilton, USA). The sample compartment was stirred at $240 \mathrm{rpm}$ for $90 \mathrm{~min}$ with an IKA magnetic stirrer (Wilmington, NC, USA). During the extraction process, the organic solvent was trapped in a space between the MF mouth and the surface of the aqueous solution vortex and the analytes were extracted from the aqueous into the organic phase. After the extraction, MF was immersed further into the sample (10 to $15 \mathrm{~mm}$ ) to push the extraction phase into the narrow stem of the device. The solvent was then transferred into a glass micro vial and evaporated to dryness by a gentle stream of nitrogen gas. The residual re-dissolved into $50 \mu \mathrm{L}$ acetonitrile, diluted to $100 \mu \mathrm{L}$ with deionized water and introduced into the HPLC for analysis.

\subsection{HPLC analysis}

Chromatographic analysis was carried out on an Agilent 1100 HPLC system (California, USA). The HPLC system was equipped with a G1379A Micro Vacuum degasser, a G1312A Binary pump, a G1158A six-port two-position injection valve with a
$100 \mu \mathrm{L}$ sample loop, and an Agilent G1314A variable wavelength detector (VWD). Chromatographic data were recorded and analyzed using ChemStation software (version Rev.A.09.03 [1417]). A C18 column $(5 \mu \mathrm{m}, 4.6 \mathrm{~mm} \times 250 \mathrm{~mm})$ from Agilent Eclipse plus was applied to separate the analytes under isocratic elution conditions. A Mixture of $25 \mathrm{mmol} \mathrm{L}^{-1}$ phosphate buffer $(\mathrm{pH}=3)$ and acetonitrile $(37: 63, \mathrm{v} / \mathrm{v})$ with a flow rate of 1.0 $\mathrm{mL} \min ^{-1}$ was used as the mobile phase. The injection volume was $100 \mu \mathrm{L}$ for all standards and samples and detection was performed at wavelength of $240 \mathrm{~nm}$.

\section{Results and Discussion}

\subsection{Type of extraction solvent}

The type of extraction solvent is a crucial parameter affecting the performance of the LPME method. Many of the solvents suitable for LPME have densities lower than water (Saleh et al. 2009) and their extraction efficiency could be evaluated in the MF-LPME method. In this study a number of different organic solvents less dense than water including: toluene, $n$-hexane, $n$-heptane and the mixture of DCM and $n$-hexane $(3: 7 \mathrm{v} / \mathrm{v})$ were selected and examined for MF-LPME of target analytes. A series of spiked sample solutions were extracted using $400 \mu \mathrm{L}$ of each extraction solvent. The extraction was performed according to the procedure mentioned in 2.2. The highest peak areas were obtained by toluene and as a result toluene was selected for subsequent experiments.

\subsection{Experimental design}

Central composite design (CCD) has been wildly used for the optimization of different microextraction methods. In this work, CCD was used (the DesignExpert 7.0.0, DOE software, Stat-Ease, Inc., Minneapolis, MN, USA) to optimize four effective 
MF-LPME parameters including the volume of extraction solvent, sample $\mathrm{pH}$, extraction time and salt concentration. It comprises a factorial design $\left(2^{f}\right)$ augmented with $(2 f)$ star point, where $f$ is the number of factors to be optimized, and with (n) central points. The star points are situated at $+\alpha$ and $-\alpha$ from the center of the experimental domain. In order to establish the rotatability of the experimental design, $\alpha$ was set at $\alpha=\sqrt[4]{2 \mathrm{f}}= \pm 2$ (Montgomery 2001, Johansson et al. 2009, Sarabia and Ortiz 2009). The total number of design point needed $(\mathrm{N})$ is determined by the following equation:

$N=2^{f}+2 f+n$

In this study, in total, 30 experiments in 3 blocks were performed for four factors $(n=6)$. According to the design, each of the four factors (A, B, C and D) was studied at five levels which were shown in Table 1. A quadratic regression model, on the basis of a multiple linear regression (MLR), should be applied to relate the responses and the variables. The second order polynomial with the most reasonable statistics, that is higher $F$ and $R$ values and low standard error were considered as the satisfactory response surface model to fit the experimental data. This model is represented in Eq. (2); include four main effects, one factor interaction effect and one curvature effect.

$\log _{10}(\mathrm{R})=-0.33-0.47 \mathrm{~A}+0.060 \mathrm{~B}+0.13 \mathrm{C}-$

Where $\mathrm{R}$ is the sum of relative peak areas for the analytes as a function of $\mathrm{A}$ (sample $\mathrm{pH}$ ), $\mathrm{B}$ (volume of extraction solvent), $\mathrm{C}$ (salt concentration (w/v)) and $\mathrm{D}$ (extraction time). The analysis of variance (ANOVA) table was used to evaluate the model and the significance of the effects (Table 2).

Table 1: Factors, their symbols and levels for central composite design

\begin{tabular}{lccccccc}
\hline Factor & Symbol & \multicolumn{5}{c}{ Level } \\
\cline { 3 - 8 } & & & $-\alpha$ & -1 & 0 & +1 & $+\alpha$ \\
\hline Sample $\mathrm{pH}$ & $\mathrm{A}$ & 1 & 2 & 3 & 4 & 5 \\
Volume of extraction solvent $(\mu \mathrm{L})$ & $\mathrm{B}$ & 200 & 300 & 400 & 500 & 600 \\
Salt Concentration $(\mathrm{w} / \mathrm{v})$ & $\mathrm{C}$ & 0 & 5 & 10 & 15 & 20 \\
Extraction time (min) & $\mathrm{D}$ & 30 & 50 & 70 & 90 & 110 \\
\hline
\end{tabular}

Table 2: Analysis of variance (ANOVA) for central composite design

\begin{tabular}{cccccc}
\hline Source & Sum of squares & d.f. $^{\text {a }}$ & Mean Square & $\boldsymbol{F}$-Value & $\begin{array}{c}\boldsymbol{p} \text {-value } \\
\text { Prob }>\boldsymbol{F}\end{array}$ \\
\hline Block & 0.037 & 2 & 0.018 & & \\
Model & 6.18 & 6 & 1.03 & 105.87 & $<0.0001$ \\
A & 5.30 & 1 & 5.30 & 544.07 & $<0.0001$ \\
B & 0.087 & 1 & 0.087 & 8.96 & 0.0069 \\
C & 0.44 & 1 & 0.44 & 44.77 & $<0.0001$ \\
D & $1.464 \mathrm{E}-003$ & 1 & $1.464 \mathrm{E}-003$ & 0.15 & 0.7020 \\
AD & 0.084 & 1 & 0.084 & 8.67 & 0.0078 \\
$\mathrm{~A}^{2}$ & 0.28 & 1 & 0.28 & 28.60 & $<0.0001$ \\
\hline
\end{tabular}




\begin{tabular}{ccccccc}
\hline Residual & 0.20 & 21 & $9.734 \mathrm{E}-003$ & & & \\
Lack of Fit & 0.19 & 18 & 0.011 & 2.08 & 0.3009 & not significant \\
Pure Error & 0.015 & 3 & $5.063 \mathrm{E}-003$ & & \\
Total & 6.42 & 29 & & & \\
\hline
\end{tabular}

${ }^{a}$ Degree of freedom

Values of "Prob $>F$ " less than 0.10 indicate model terms are significant. The quality of model fitting was expressed by the coefficient of determination, $R^{2}$, and adjusted $R^{2}$ values, which were 0.9680 and 0.9589 , respectively. From the ANOVA summary, the model was found to be significant, with a $p$-value less than 0.0001 . The lack-of-fit (LOF) $p$-value of 0.3009 indicates that the LOF was not significant relative to the pure error. According to the Eq. (2), the factors affect the response in the following order: $\mathrm{pH}$ of sample solution > amount of salt in aqueous solution > volume of extraction solvent. Volume of extraction solvent and concentration of salt in water sample have positive effect on the response, but sample $\mathrm{pH}$ has negative effect. It means that, increasing in concentration of $\mathrm{NaCl}$ (salting-out effect) and extraction solvent volume lead to enhancement of the extraction efficiency. Fig. 1 demonstrates three-dimensional plots (3D) of the response surface model. As shown in Figure 1, concurrently decreasing of sample $\mathrm{pH}$ and increasing of extraction time within the investigated ranges enhances the performance of the microextraction process. Since the neutral and more hydrophobic form of CPAAs (pKa values of 2.73 and 3.07 for 2, 4-D and MCPA, respectively) are dominant in acidic $\mathrm{pH}$, higher extraction efficiencies are expected at lower $\mathrm{pH}$ values (Figure 1).

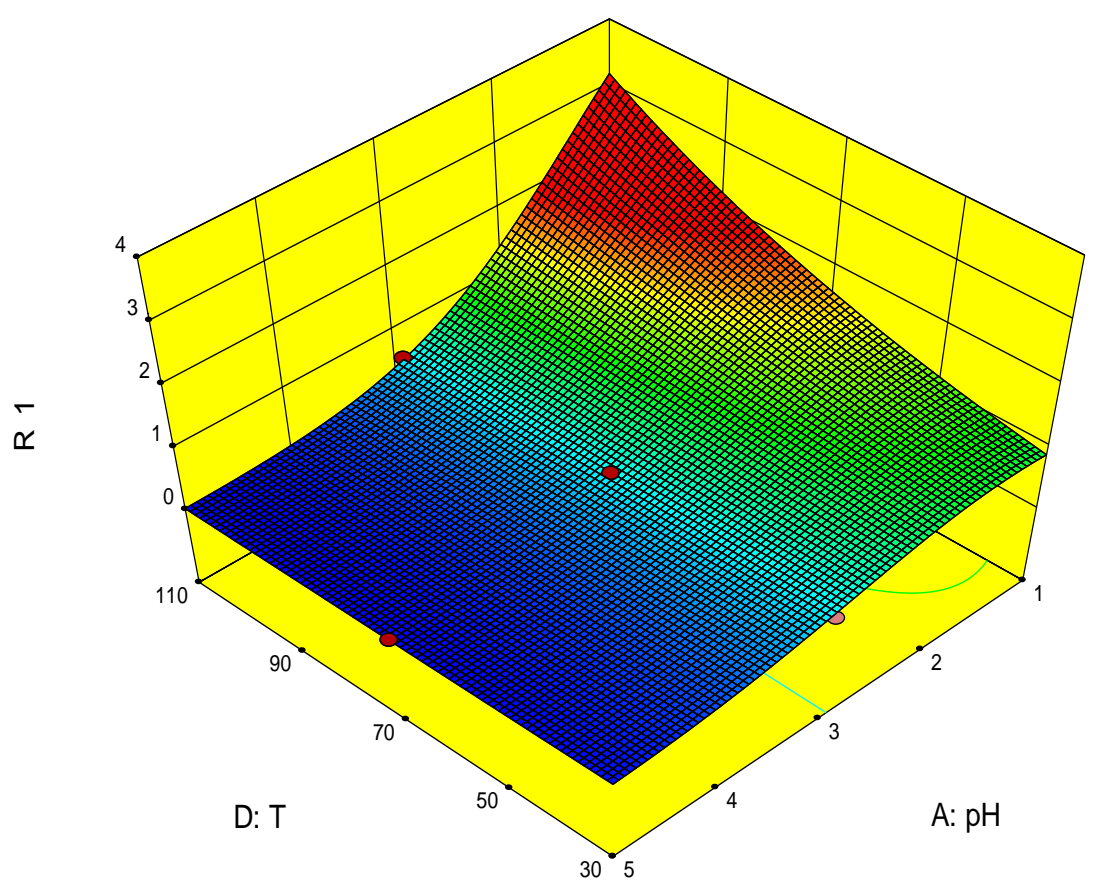

Fig. 1: Demonstration of three-dimensional (3D) plot of the response surface model 
According to the results from the optimization study, the optimal conditions were obtained as follows: sample $\mathrm{pH}, 1.5$; volume of extraction solvent, $540 \mu \mathrm{L}$; salt $(\mathrm{NaCl}), 15 \%(\mathrm{w} / \mathrm{v})$ and extraction time, $90 \mathrm{~min}$. The results show that a good agreement exists between the predicted values by the model and the experimental values at the points of interest.

\subsection{Method validation}

\subsubsection{Analytical performance}

In order to validate the applicability of the proposed MF-LPME method, the figures of merit including preconcentration factors (PFs), linear ranges (LRs), limit of detections (LODs) and limit of quantifications (LOQs) for the extraction of CPAAs in spiked aqueous sample were investigated under optimum conditions. The results are shown in Table 3.

The linearity was observed over the range of 1.40-1000 $\mathrm{ng} \mathrm{mL}^{-1}$ for 2, 4-D and 1.43-1000 $\mathrm{ng} \mathrm{mL}^{-}$

${ }^{1}$ for MCPA with regression coefficients $\left(\mathrm{R}^{2}\right)$ better than 0.997. The LODs, calculated at a signal -tonoise $(\mathrm{S} / \mathrm{N})$ ratio of 3 , were 0.42 and $0.43 \mathrm{ng} \mathrm{mL}^{-1}$ for 2, 4-D and MCPA, respectively. The PF values were 66 and 80 for 2, 4-D and MCPA, respectively.
The precision of the method was evaluated in terms of repeatability which was less than $11.1 \%(n=5)$. A comparison of the present method with previously published methods for extraction of chlorophenoxyacetic acid herbicides is summarized in Table 4 (Rodríguez Pereiro et al. 2004, Quintana et al. 2007, Saraji and Farajmand 2008, Tsai and Huang 2009). Figures of merit obtained by MFLPME are comparable with dispersive liquidliquid-liquid microextraction coupled with liquid chromatography-UV detection (DLLLME-LC-UV) (Tsai and Huang 2009). Although, techniques coupled with gas chromatography-mass spectrometry detection (GC-MS) have very low LODs (in the range of $\mathrm{n} \mathrm{L}^{-1}$ ) (Quintana et al. 2007, Saraji and Farajmand 2008), determination of most of the herbicides using GC-MS needs a derivatization step which increases the cost and time of analysis. In addition, solid-phase microextration (SPME) and stir-bar sorptive extraction (SBSE) suffer from possible memory effect problems. Elimination of the instability of extraction solvent drop during the extraction process and capability of analysis of large volumes of samples are significant features of the proposed MF-LPME in contrast to single-drop microextrcation (SDME) method.

Table 3: Figures of merit for the MF-LPME of target analytes

\begin{tabular}{|c|c|c|c|c|c|c|}
\hline \multirow{2}{*}{ Analyte } & \multicolumn{2}{|c|}{ Linearity } & \multirow[t]{2}{*}{$\begin{array}{c}\mathbf{L O D}^{\mathbf{a}} \\
\left(\mathrm{ng} \mathrm{mL}^{-1}\right)\end{array}$} & \multirow[t]{2}{*}{$\begin{array}{c}\mathbf{L O Q}^{\mathbf{b}} \\
\left(\mathrm{ng} \mathrm{mL}^{-1}\right)\end{array}$} & \multirow[t]{2}{*}{$\begin{array}{c}\text { RSD\% } \\
(n=5)\end{array}$} & \multirow[t]{2}{*}{$\mathbf{P F}^{\mathrm{c}}$} \\
\hline & $\mathrm{LR}\left(\mathrm{ng} \mathrm{mL^{-1 }}\right)$ & $\mathrm{R}^{2}$ & & & & \\
\hline 2,4-D & $1.40-1000$ & 0.997 & 0.42 & 1.40 & 11.1 & 66 \\
\hline МСРA & $1.43-1000$ & 0.996 & 0.43 & 1.43 & 10.4 & 80 \\
\hline
\end{tabular}

${ }^{a}$ Limit of detection ( $\mathrm{LOD}=3 \times S_{b} / \mathrm{m}$, where $\mathrm{Sb}$ is the standard deviation of the blank and $\mathrm{m}$ is the slope of the calibration curve).

${ }^{\mathrm{b}}$ Limit of quantification $(\mathrm{LOQ}=10 \times \mathrm{Sb} / \mathrm{m})$

${ }^{\mathrm{c}}$ Preconcentration factor. 
Table 4: Comparison of analytical performance data of proposed method with other methods applied for the analysis of chlorophenoxyacetic acid herbicides

\begin{tabular}{|c|c|c|c|c|c|c|}
\hline Method & Herbicides & $\begin{array}{c}\mathbf{L R} \\
\left(\mathrm{ng} \mathrm{mL} L^{-1}\right)\end{array}$ & $\begin{array}{c}\text { LOD } \\
\left(\mathrm{ng} \mathrm{mL}^{-1}\right)\end{array}$ & $\begin{array}{c}\text { RSD\% } \\
(\mathrm{n}=5)\end{array}$ & PF & Ref. \\
\hline SPME/ GC-MS ${ }^{\mathbf{a}}$ & 2,4-D, MCPA & $30-1000$ & $1-2$ & $2.9-7$ & - & $\begin{array}{l}\text { Rodríguez Pereiro et } \\
\text { al. } 2004\end{array}$ \\
\hline $\mathrm{SBSE}^{\mathrm{b}} / \mathrm{GC}-\mathrm{MS}$ & $2,4-\mathrm{D}$ & $0.16-1.66$ & 0.066 & $12-13$ & $18-36$ & Quintana et al. 2007 \\
\hline SDME / GC-MS & 2,4-D, MCPA & $0.01-0.24$ & $\begin{array}{l}0.007- \\
0.024\end{array}$ & $3.7-7.7$ & $77-84$ & $\begin{array}{l}\text { Saraji and Farajmand } \\
2008\end{array}$ \\
\hline DLLLME/ LC-UV & 2,4-D, MCPA & $0.16-1000$ & $0.13-1.31$ & $4.2-12.2$ & - & Tsai and Huang 2009 \\
\hline MF-LPME/ LC-VWD & 2,4-D, MCPA & $1.40-1000$ & 0.42 & $10.4-11.1$ & $66-80$ & This work \\
\hline
\end{tabular}

${ }^{\text {a }}$ Solid-phase microextraction/gas chromatography-mass spectrometery.

${ }^{\mathrm{b}}$ Stir-bar sorptive extraction.

${ }^{c}$ Single-drop microextraction.

${ }^{\mathrm{d}}$ Dispersive liquid-liquid-liquid microextraction/liquid chromatography-ultraviolet detection.

\subsubsection{Real sample analysis}

MF-LMPE was applied for determining of target compounds in different environmental samples including river water (Rasht, Iran), tap water (Tehran, Iran) and seawater (Caspian Sea) samples. All samples were collected in amber glass container and maintained in dark at $4{ }^{\circ} \mathrm{C}$ until analysis. To evaluate the accuracy and matrix effect of the present method, the relative recoveries of the CPAAs were investigated in spiked real samples at analyte concentration of $50 \mathrm{ng} \mathrm{mL}{ }^{-1}$ and the results were depicted in Table 5. The results showed that the relative recoveries were in the ranges of $89 \%$ to $110 \%$, indicated that the matrices of natural water samples had no significant effect on the extraction efficiency of this method.

Figure 2 shows the HPLC-UV chromatograms of sea water samples before (a) and after (b) spiking at the concentration of $50 \mathrm{ng} \mathrm{mL}^{-1}$ of each CPAA.

Table 5: Results obtained from analysis of some natural water samples.

\begin{tabular}{lcccccc}
\hline Real samples & Analyte & $\begin{array}{c}\text { Initial } \\
\text { concentration } \\
\left(\mathrm{ng} \mathrm{mL}^{-1}\right)\end{array}$ & $\begin{array}{c}\text { Added } \\
\left(\mathrm{ng} \mathrm{mL}^{-1}\right)\end{array}$ & Found & RR\% $^{\mathbf{a}}$ & RSD\% \\
\hline Tap water & $2,4-\mathrm{D}$ & $\left.\mathrm{nd} \mathrm{mL}^{-1}\right)$ & & & \\
& $\mathrm{MCPA}$ & $\mathrm{nd}$ & 50 & 51.8 & 103.0 & 7.4 \\
River water & $2,4-\mathrm{D}$ & $\mathrm{nd}$ & 50 & 52.0 & 104.0 & 24.8 \\
& $\mathrm{MCPA}$ & $\mathrm{nd}$ & 50 & 46.6 & 93.4 & 17.7 \\
Sea water 1 & 2,4-D & nd & 50 & 46.6 & 89.0 & 17.7 \\
& MCPA & nd & 50 & 45.5 & 90.9 & 5.7 \\
Sea water 2 & 2,4-D & nd & 50 & 54.9 & 110.0 & 18.2 \\
& MCPA & nd & 50 & 55.0 & 110.0 & 13.1 \\
\hline
\end{tabular}

${ }^{\mathrm{a}}$ Relative recovery $\left(\mathrm{RR} \%=\left(\mathrm{C}_{\text {found }}-\mathrm{C}_{\text {initial }} / \mathrm{C}_{\mathrm{add}}\right) \times 100\right)$.

${ }^{\mathrm{b}}$ Not detected. 

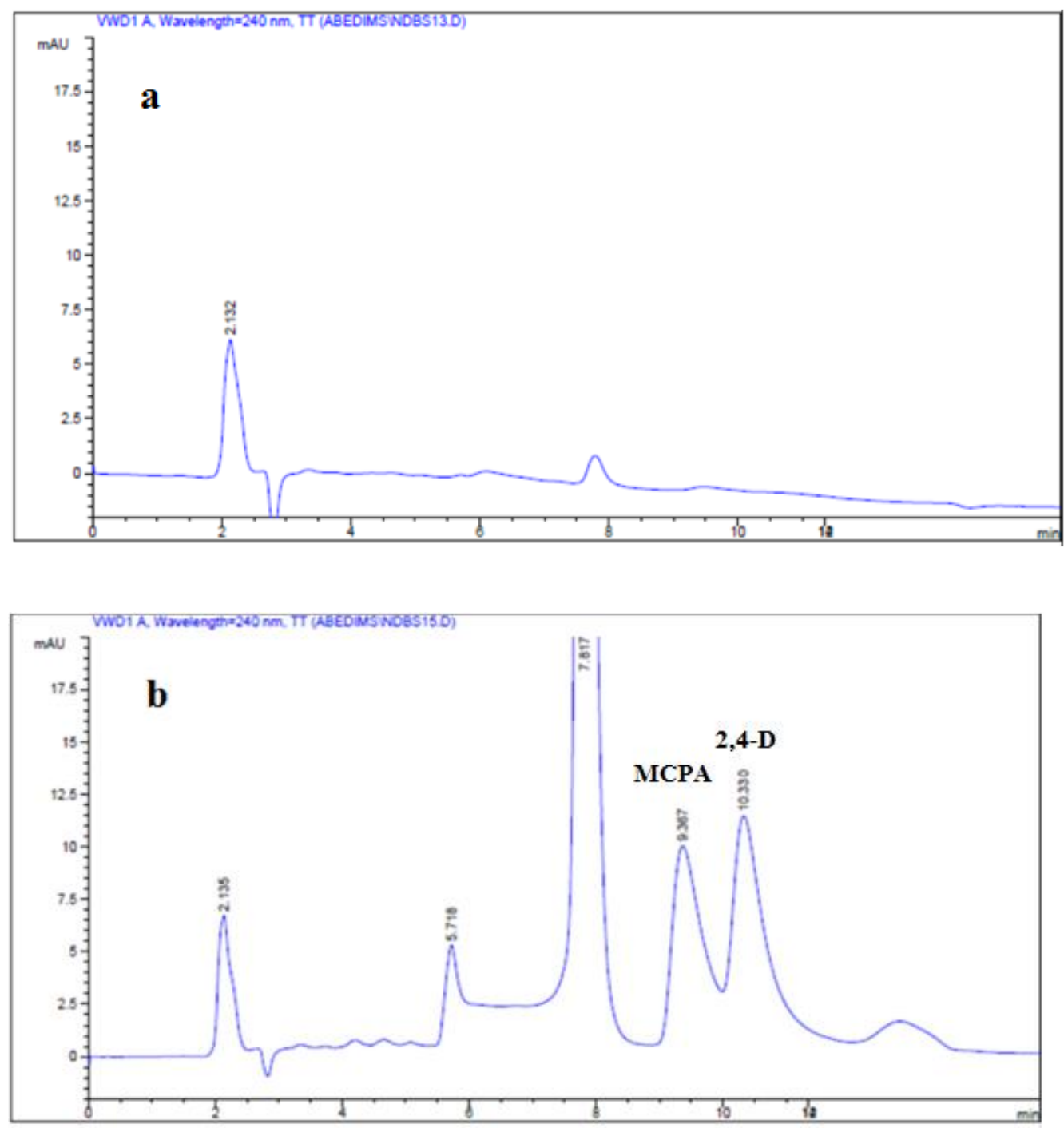

Fig 2: Typical HPLC-UV chromatograms of seawater befor (a) and after (b) spiking at the concentration of $50 \mu \mathrm{g} \mathrm{L}-1$ of each CPAA

\section{Conclusion}

In this study, microfunnel-supported liquid-phase microextraction method was optimized for the determination of some chlorophenoxyacetic acids from natural water samples. The possibility of utilizing large volume of water sample and small volume of extraction solvent resulted in achieving low limits of detection in this method. In MF-LPME, during the extraction, the wide mouth of the device is tangent to the surface of the sample through edges which leads to a minimum interference in mixing efficiency and maximum possible surface contact between organic solvent droplet and water sample with almost no solvent loss by evaporation. The study and the optimization of the experimental variables were performed using a central composite design and response surface methodology. Finally, good LODs and linearity and acceptable repeatability offered by MF-LMPE method make it as a feasible alternative to the standard techniques, such as SPE, SPME and other kind of LPME for the extraction of CPAAs residues in natural water samples. 


\section{Acknowledgements}

We thank Iranian National Institute for Oceanography and Atmospheric Science (INIOAS) for providing lab space and analytical instruments for performing this research.

\section{References}

Barcelo, D.; Hennion, M., 1997. Trace Determination of pesticides and their Degradation Products in Water. Elsevier, Amsterdam.

Leganes, F.; Fernandez-Valiente, E.; 1992. Effects of phenoxy acetic herbicides on growth, photosynthesis, and nitrogenase activity in cyanobacteria from rice fields. Arch Environ Contam Toxicol 22 (1):130-134. https://doi.org/10.1007/BF00213311

Ogg Jr, A.G.; Young, F.L.; 1991. Effects of Preplant Treatment Interval and Tillages on Herbicide Toxicity to Winter Wheat (Triticum aestivum). Weed Technology. 5 (2):291-296. https://doi.org/10.1017/S0890037X00028128

Alan, C.Y.; John, W.W.; Mark, M.K.; Frank, R.; Walls, Jr. 1991. Soybean (Glycine max) Response to Postemergence Herbicide Mixtures Containing 2,4-DB. Weed Technology. 5 (1):43-47. https://doi.org/10.1017/S0890037X00033236

Ware, G.W.; 2000. The Pesticide Book. 5th ed. California Thomson Publications.

Alexander, H.C.; Gersich, F.M.; Mayes, M.A. 1985. Acute toxicity of four phenoxy herbicides to aquatic organisms. Bull Environ Contam Toxicol. 35 (3):314-321. https://doi.org/10.1007/BF01636516

Yamini, Y.; Saleh, A. 2013. Ultrasound-assisted emulsification microextraction combined with injection-port derivatization for the determination of some chlorophenoxyacetic acids in water samples. J Sep Sci. 36 (14):2330-2338.

https://doi.org/10.1002/jssc.201300340

Grabińska-Sota, E.; Wiśniowska, E.; Kalka, J. 2003.

Toxicity of Selected Synthetic Auxines 2, 4-D and MCPA derivatives to broad-leaved and cereal plants. Crop Protection. 22:355-360.

https://doi.org/10.1016/S0261-2194(02)00178-3

Butz, S., Heberer, T., Stan, H.J. 1994. Determination of phenoxyalkanoic acids and other acidic herbicides at the low ppt level in water applying solid-phase extraction with RP-C18 materi. Journal of Chromatography A. 677 (1):63-74. https://doi.org/10.1016/0021-9673(94)80545-8

Majzik, E.S.; Tóth, F.; Benke, L.; Kiss, Z. 2006. SPE-LC-MS-MS Determination of Phenoxy Acid Herbicides in Surface and Ground Water. Chromatographia. 63 (13):S105-S109. https://doi.org/10.1365/s10337-006-0786-X

Ebrahimi, R.; Feizbakhsh. A.; Es'haghi, A. 2016. Extraction and Derivatization of Chlorophenoxy Acid Pesticides: Performing Two DLLME with One Extracting Phase. Chromatographia. 79 (7):515-520.

https://doi.org/10.1007/s10337-016-3042-z

Wells, M.J., Yu, L.Z. 2000. Solid-phase extraction of acidic herbicides. Journal of chromatography A. 885 (1-2):237-250. https://doi.org/10.1016/S0021-9673(00)00206-5

Ding, W.H.; Liu, C.H.; Yeh, S.P. 2000. Analysis of chlorophenoxy acid herbicides in water by largevolume on-line derivatization and gas chromatography-mass spectrometry. Journal of chromatography A. 896 (1-2):111-116. https://doi.org/10.1016/S0021-9673(00)00576-8

Rodríguez. I.; Rubí, E.; González, R.; Quintana, J.B.; Cela, R. 2005. On-fibre silylation following solidphase microextraction for the determination of acidic herbicides in water samples by gas 
chromatography. Analytica Chimica Acta. 537 (1-2):259-266.

\section{https://doi.org/10.1016/j.aca.2004.12.083}

Farhadi, K.; Matin. A.A.; Hashemi, P. 2008. LC Determination of Trace Amounts of Phenoxyacetic Acid Herbicides in Water after Dispersive LiquidLiquid Microextraction. Chromatographia. 69 (1):45-49.

https://doi.org/10.1365/s10337-008-0815-Z

Wu, J.; Ee, K.H.; Lee, H.K. 2005. Automated dynamic liquid-liquid-liquid microextraction followed by high-performance liquid chromatography-ultraviolet detection for the determination of phenoxy acid herbicides in environmental waters. Journal of Chromatography A. 1082 (2):121-127. https://doi.org/10.1016/j.chroma.2005.05.077

Esrafili, A.; Yamini, Y.; Ghambarian, M.; Moradi, M.; Seidi, S. 2011. A novel approach to automation of dynamic hollow fiber liquid-phase microextraction. J Sep Sci. 34 (8):957-964.

https://doi.org/10.1002/jssc.201000913

Hassan, J.; Shamsipur, M.; Es'haghi, A.; Fazili, S. 2011. Determination of Chlorophenoxy Acid Herbicides in Water Samples by Suspended Liquid-Phase Microextraction-Liquid Chromatography. Chromatographia. 73 (9):9991003.

https://doi.org/10.1007/s10337-011-1973-y

Čabala, R.; Bursová, M. 2012. Bell-shaped extraction device assisted liquid-liquid microextraction technique and its optimization using response-surface methodology. Journal of chromatography A. 1230:24-29.

https://doi.org/10.1016/j.chroma.2012.01.069

Saleh, A.; Sheijooni Fumani, N.; Molaei, S. 2014. Microfunnel-supported liquid-phase microextraction: application to extraction and determination of Irgarol 1051 and diuron in the Persian Gulf seawater samples. Journal of chromatography A. 1356:32-37.

https://doi.org/10.1016/j.chroma.2014.06.057

Saleh, A.; Yamini, Y.; Faraji, M.; Rezaee, M.; Ghambarian, M. 2009. Ultrasound-assisted emulsification microextraction method based on applying low density organic solvents followed by gas chromatography analysis for the determination of polycyclic aromatic hydrocarbons in water samples. Journal of Chromatography A. 1216 (39):6673-6679.

https://doi.org/10.1016/j.chroma.2009.08.001

Montgomery, D.C. 2001. Desing and Analysis of Exprimental, 5th edition, johan wily And Sons Chiester, uk.

Johansson, E.; Kettaneh-Wold, N.; Wikstrom, C.; Wold, S.; Ericksson, L. 2009. Desing of Experiments principles and Application, 3rd edition, Umetric academy.

Sarabia, L.A.; Ortiz, M.C. 2009. Comperehensive Chemometrics: Chemical and Biochemical Data Analysis RESPONSE Surface Methodology, Elsevier B. V, Amsterdam, Netherland. https://doi.org/10.1016/B978-044452701-1.00083$\underline{1}$

Rodríguez Pereiro, I.; González Irimia, R.; Rubí Cano, E.; Cela Torrijos, R. 2004. Optimisation of a gas chromatographic-mass spectrometric method for the determination of phenoxy acid herbicides in water samples as silyl derivatives. Analytica Chimica Acta. 524 (1-2):249-256. https://doi.org/10.1016/j.aca.2004.03.091

Quintana, J.B.; Rodil, R.; Muniategui-Lorenzo, S.; Lopez-Mahia, P.; Prada-Rodriguez, D. 2007. Multiresidue analysis of acidic and polar organic contaminants in water samples by stir-bar sorptive extraction-liquid desorption-gas chromatography- 
mass spectrometry. Journal of chromatography A. 1174 (1-2):27-39.

https://doi.org/10.1016/j.chroma.2007.07.088

Saraji, M.; Farajmand, B. 2008. Application of single-drop microextraction combined with inmicrovial derivatization for determination of acidic herbicides in water samples by gas chromatography-mass spectrometry. Journal of chromatography A. 1178 (1-2):17-23.

https://doi.org/10.1016/j.chroma.2007.11.056
Tsai, W.C.; Huang, S.D. 2009. Dispersive liquidliquid-liquid microextraction combined with liquid chromatography for the determination of chlorophenoxy acid herbicides in aqueous samples. Journal of chromatography A. 1216 (45):7846-7850.

https://doi.org/10.1016/j.chroma.2009.09.057 
